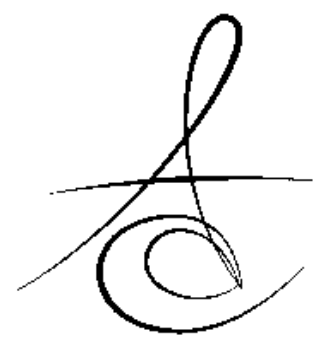

\title{
ZİGOMA İMPLANTLARI
}

\section{ZYGOMATIC IMPLANTS}

Yrd. Doç. Dr. M.Melih ÖMEZLI*

Prof. Dr. Ümit ERTAŞ**

Makale Kodu/Article code: 1056

Makale Gönderilme tarihi: 28.01.2013

Kabul Tarihi: 09.09.2013

\section{ÖZET}

Erken diş kayıpları, periodontal hastalıklar, tümör rezeksiyonu gibi sistemik ve lokal faktörler neticesinde maksillada ileri derecede horizontal ve vertikal kemik rezorbsiyonu meydana gelebilmektedir. İleri derecede atrofik maksillanın rehabilitasyonu için geleneksel tam protez ya da kemik grefti kullanılarak yapılan implant destekli protez tedavi seçenekleri arasındadır. Bununla birlikte, 1998 yılında Branemark tarafından ileri derecede atrofik maksillaya sahip hastalarda alternatif bir tedavi seçeneği olarak zigoma implantları tanıtılmıştır. Literatürde farklı yazarlar tarafından yapılan araştırmalarda zigoma implantlarının başarı oranının \% 82-100 arasında olduğu bildirilmiştir. Bu sonuçlar zigoma implantlarının geçerli bir tedavi seçeneği olduğunu göstermiştir.

$\mathrm{Bu}$ derlemenin amacı, zigoma implantlarının endikasyon, avantaj, dezavantajlarının yanı sıra başarı oranları ve olası komplikasyonları hakkında bilgi vermektir.

Anahtar Kelimeler: implant, zigoma, rezorbsiyon.

\section{GİRIŞ}

Tümör cerrahisinden sonra meydana gelen defekt bulunan ya da ileri derecede rezorbe dişsiz maksillaya sahip hastalarda cerrahi ve protetik rehabilitasyon oldukça güç olabilmektedir. ${ }^{1-4}$ Rehabilitasyonun amacı sadece kabul edilebilir bir kozmetik sağlamak değil, aynı zamanda yutma, çiğneme ve fonasyon gibi oral fonksiyonların da düzeltilmesidir. ${ }^{1,2}$, 5 İleri derecede rezorbe maksillaya sahip hastalarda standart implantların yerleştirilmesi için yeterli kemik

\section{ABSTRACT}

Severe vertical and horizontal bone resorption in the maxilla may be caused by a complex interaction of local and systemic factors, such as early tooth loss, periodontal disease and tumour resection. Treatment options for the rehabilitation of the severely atrophic maxilla include conventional complete dentures and implant-supported prosthesis with bone grafts. However, zygomatic implants were described by Branemark in 1998 as a suitable alternative for patients with atrophic maxilla. In literatures, the success rate of the zygoma implants obtained by different authors varies between $82 \%$ and $100 \%$, indicating the technique as a valid treatment option.

The aim of this compilation is to give information concerning with indications, the advantages, disadvantages as well as potential complications and the success rate of the zygomatic implants.

Key Words: implant, zygoma, resorption.

* Ordu Üniversitesi Diş Hekimliği Fakültesi Ağız Diş Çene Cerrahisi AD

* Atatürk Üniversitesi Dis Hekimliăi Fakültesi Aăız Dis Cene Cerrahisi AD

hacmi bulunmamaktadır. Başarılı bir rehabilitasyon sağlamak için kemik hacminin artırımasında blok ya da alveoler split greftleme, iliak kanat grefti, interpozisyonel greftlemeyle beraber Le Fort I osteotomisi, sinüs lifting ve bu prosedürlerin kombinasyonu gibi çeşitli tedavi yaklaşımları kullanılmaktadır. ${ }^{6-9}$ Bu tedavi prosedürlerinin ağrı ve hassasiyetle beraber hastada konforu azaltması, hasar riskinin yüksek olması, birden fazla cerrahi gerektirmesi, tedavi periyodunu uzatması gibi dezavantajları bulunmaktadır. ${ }^{3,11}$ Bu olası komplikasyonlar ve greftlemeden kaynaklanan tedavi süresinin 
uzaması gibi nedenlerden dolayı atrofik maksillanın protetik rehabilitasyonu için distraksiyon osteogenezi ve zigoma implantları gibi greftsiz tedavi yöntemleri kullanılmaktadır. ${ }^{12}$

1997 yilında Weischer ve ark. ${ }^{13}$ maksillektomi yapılan hastalarda protetik rehabilitasyonda destek yapı olarak zigomanın kullanılabileceğini vurgulamışlardır. Bununla birlikte, ileri derecede rezorbe alveol kretlerinde alternatif tedavi seçeneği olarak zigoma implantlarını ilk olarak 1998 yılında Branemark ${ }^{14}$ tanıtmıştır. Standart implantlar gibi titanyumdan yapılan zigoma implantları 30-55 mm arasında değişen uzunluğa ve kemikle maksilla arasındaki açılanmayı tolere edebilmek için 45 derecelik bir boyun kısmına sahiptir. ${ }^{8,15}$ (Resim 1)

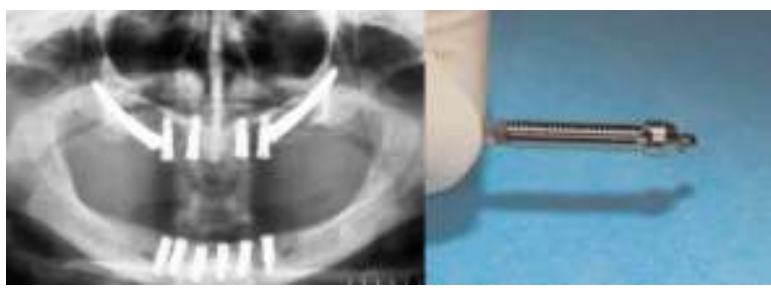

Resim 1. Zigoma implantı ve radyografik görüntüsü ${ }^{17}$

$\mathrm{Bu}$ derlemede, defekt bulunan ya da ileri derecede rezorbe maksillaya sahip hastaların protetik rehabilitasyonunda günümüzde alternatif tedavi seçeneği olarak başvurulan zigoma implantlarının endikasyon, avantaj, dezavantaj, uygulama tekniği ve başarı oranları hakkında bilgi verilmiştir.

\section{Zigomanın Anatomisi}

Zigomatik kemik küçük, 4 köşeli bir yapıdır ve orta yüzdeki en önemli destek yapıyı oluşturmaktadır. Fronto-sfenoidal, orbital, maksillar ve temporal olmak üzere dört çıkıntısı vardır. Sfenoid kemikle lateralde, frontal kemikle superiorda, maksilla ile medial ve inferiorda ilişkidedir. Temporal kemikle birlikte zigomatik arkı oluşturur. Frontal kemikle ve maksilla ile birleştiği alanlar en kalın ve en kuvvetli olduğu yerlerdir. ${ }^{8}$

\section{Zigoma İmplantlarının Endikasyonları}

İleri derecede alveol kemik rezorbsiyonu:

Periodontal hastalık, erken diş kayıpları, enfeksiyon, travma gibi lokal ya da sistemik faktörler sonucunda alveoler yapıda ileri derecede vertikal ve horizontal rezorbsiyon meydana gelebilmektedir.,8,15,16 $\mathrm{Bu}$ tip hastalar çoğu zaman greft konularak standart implant yerleştirilmesine aday olmasına rağmen bazen çeşitli sistemik ya da lokal sebeplerden dolayı greftleme imkanı olmamaktadır. ${ }^{2,3,11,17,18}$

Greft uygulamalarında kullanılan materyaller immünolojik orjinlerine göre otojen greftler, izojen greftler, allogreftler ve xenogreftler olarak sınıflandırılabilmektedir. ${ }^{19,}{ }^{20}$ Alveoler atrofi ve kemik defektlerinin tedavisinde otojen kemik greftleri ile rekonstrüksiyon her ne kadar altın standart olarak kabul edilse de, intraoral donör sahalarda fazla miktarda greft elde edilememesi, iliak krest gibi ekstraoral donör sahalarda ise sensitif sinir hasarı ve morbidite oluşma riski gibi dezavantajlar bulunmaktadır. ${ }^{19-21}$

Greft uygulayarak yapılan rehabilitasyonun bir diğer dezavantajı; greft uygulamasını takiben yaklaşık 4 aylık bir iyileşme periyodunun olması ve ardından yerleştirilen implantın 4-8 aylık bir osteointegrasyon periyodunun olmasıdır. Dolayısıyla ilk cerrahi yapılması ile protetik aşama arasında 12 aylık gibi uzun bir dönem geçmesi zigoma implantları gibi greftsiz tedavi seçeneklerini ön plana çıkartmaktadır. 2, 3, 7

Sendromlu Hastalar: Zigoma implantları için bir diğer endikasyon kleidokraniyal dizostozis ya da ektodermal displazi gibi posterior maksilla atrofisiyle beraber çok sayıda diş eksikliği bulunan hastalardır.8, 18,22 Penarrocha ve ark. ${ }^{22}$ anterior maksillaya 3 standart implantla birlikte 2 zigomatik implant yerleştirdikleri ektodermal displazi bulunan hastada 18 ay sonra oral fonksiyonlarda önemli derecede düzelme tespit ettiklerini rapor etmişlerdir.

Edinilmiş ya da Konjenital Defektli Hastalar: Zigoma implantlarının uygulandığı bir diğer durum travma ya da tümör rezeksiyonunu takiben maksiller defekt oluşan hastalardır. ${ }^{1,3,8,15,18,23,24}$ Bununla birlikte erişkin damak yarığı gibi konjenital defektlerin protetik rehabilitasyonu ve tümör cerrahisinden kaynaklanan ileri derecedeki oro-nazal ilişkiye sahip hastalarda nazomaksiller rekonstrüksiyon amacıyla da uygulanmaktadır. ${ }^{18,23,25}$ Schmidt ve ark. ${ }^{23}$ maksiller rezeksiyonu takiben zigomatik implantlarla rehabilite edilen hastaların retrospektif analizini yapmışlardır. Yazarlar, parsiyel ya da total 9 maksillektomili hastaya 28 zigoma ve 10 standart implant yerleştirdikleri serilerinde, 6 zigoma ve 3 standart implant başarısız olmuş ve sonuç olarak maksilla rezeksiyonu yapılan hastalarda zigoma implantları ile standart implantların kombine kullanılmasıyla başarılı sonuçlar elde edileceğini rapor etmişlerdir. (Resim 2) 


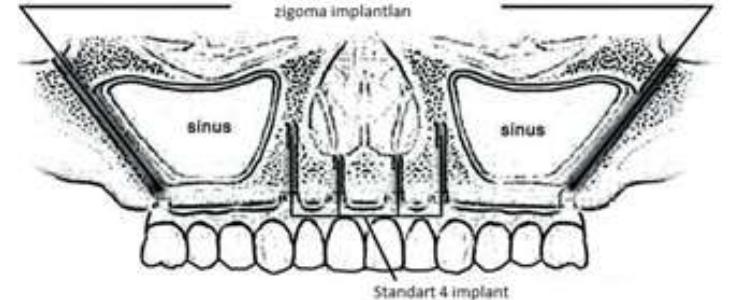

Resim 2. Standart implantlarla desteklenen zigoma implantlar. ${ }^{8}$

\section{Zigoma İmplantlarının Kontrendikasyonları}

Lokal enfeksiyon varlığı ya da kontrol altına alınamayan sistemik hastalıklar gibi geleneksel implantların kontrendikasyonları haricinde iki spesifik durum zigoma implantlarının kullanımını kısıtlamakta ya da gereksiz kılmaktadır. Birincisi, protetik rehabilitasyon için gerekli sayıda ve ebatta geleneksel implant yerleştirilebilecek kadar yeterli kemik hacmine sahip maksiller kemik bulunan hastalarda zigoma implantı uygulamak gereksizdir. İkincisi, uygun uzunlukta en az iki stabil geleneksel implant yerleştirilebilmesi için yeterli premaksiller kemik olmadığı durumlarda da zigoma implantları kontrendikedir. ${ }^{3,8,15,18}$ Bununla birlikte hastalarda herhangi bir maksiller sinüs patolojisi bulunmaması ve implantın yerleştirileceği sahada kabul edilebilir bir yumuşak doku seviyesi olması gerekmektedir. ${ }^{3,18}$

\section{Cerrahi Teknik}

Zigoma implantlarının orijinal prosedürü 1998 yılında Branemark ${ }^{14}$ tarafından tanıtılmıştır. Bu teknik, intra-sinüsal yönde zigomatik kemik içerisine 33-55 $\mathrm{mm}$ uzunluğunda implant yerleştirilmesi esasına dayanmaktadır. (Resim 3A) Zigoma implantlarının uygulama tekniği ile ilgili olarak günümüze kadar farklı yazarlar tarafından intrasinüsal, sinüs slot, extrasinüs ve extramaksiller gibi değişik yöntemler rapor edilmiştir. ${ }^{14,} 26$ Zigoma implantlarında farklı cerrahi yaklaşımların tanımlanmasının başlıca sebebi, implant başının lokalizasyonundan dolayı çiğneme esnasında mekanik direnç oluşturmak ve kabul edilebilir bir estetik sağlamaktır. ${ }^{10}$ Stella ve Wagner $^{26}$ zigomatik kemik konturuna uygun olarak yerleştirilen implantın dar bir oluk (slot) aracilığıyla sinüs boyunca pozisyonlandırımasına dayanan bir teknik tarif etmişlerdir. Bu teknikle, maksiller sinüs fenestrasyon ihtiyacının engellenmiş olduğu belirtilmiştir. ${ }^{26}$ Extra sinüs yaklaşımı özellikle belirgin bukkal konkaviteye sahip olan hastalarda kullanılan bir tekniktir. Bu yaklaşımda zigomatik implant başı alveol kretine yakın

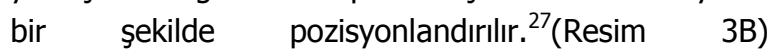
Extramaksiller yaklaşımda implant gövdesi yalnızca zigomatik arka yerleştirildiği için bu teknik diğer yaklaşımlardan oldukça farklıdır. ${ }^{28}$ Günümüzde zigoma implantlarının yerleştirilmesinde en iyi teknik için spesifik bir endikasyon bulunmamakla birlikte intrasinüs yaklaşımı en sık kullanılan yöntemdir. ${ }^{10}$

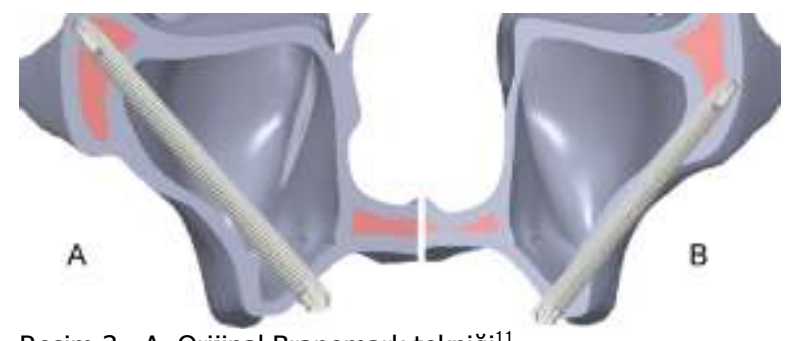

Resim 3. A. Orijinal Branemark tekniği ${ }^{11}$ B. Extrasinus tekniğ $i^{11}$

Zigoma implantları bilinçli sedasyon ve lokal anestezi ile yapılabilmesine karşın rutin olarak genel anestezi altında yapılır. İnsizyon zigomatik kemik seviyesine kadar periost ve yumuşak dokuların kaldırıması için standart Le Fort I insizyonudur. Alternatif olarak kesi kret ya da $10 \mathrm{~mm}$ palatinalden yapılabilmektedir. Böylece maksillanın lateral yüzeyi rahat görülebilecek şekilde açığa çıkar ve implant yerleştirilmeden önce alanın anatomik oryantasyonu için infraorbital foramenin belirlenmesi sağlanır. Zigomatik kemiğin lateral yüzü rehber alınarak zigomatik çentik boyunca dokuların dikkatlice yukarı diseksiyonu yapılır. İnce frez kullanılarak vertikal triangular sinüs açıklığı oluşturulur. Sinüs mukozasının tamamen elevasyonu sağlanır. Round frezi takiben pilot ve final frezler yardımıyla implantın yerleştirileceği saha hazırlanır. İmplant yerleştirilmesini kolaylaştırmak için önce implantın apikal kısmı zigomatik kemiğe 1-2 mm el parçası ile yerleştirilir. Ardından manuel taşıyıcı ile implantın kalan kısmı açılı implant başının doğru oryantasyonda olduğundan emin olarak yerleştirilir. 3, 8,15

\section{Zigoma İmplantlarında Başarı Oranı}

Zigoma implantları için başarı kriterleri; implantın fonksiyonel protez için yeterli desteği sağlaması, maksiller ve zigomatik seviyede süpürasyon, ağrı ya da diğer patolojik değiş̧ikliklerin olmaması, yeterli implant stabilitesinin bulunmasıdır. Bununla birlikte, zigoma implantlarında bazı vakalarda koronal planda minimal seviyede lateral mobilite beklenebilmektedir. ${ }^{17,}$ 29-32 Literatürde zigoma implantları ile ilgili \% 82 ile \% 100

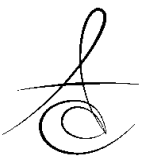


arasında değişen başarı oranları rapor edilmiştir. ${ }^{14,}$ 29, 31, 33, 34 Branemark ${ }^{14} 81$ vakada 164 zigoma implantını kapsayan serisinde hastaları 1-10 yıl takip etmiş ve başarı oranını \% 97 olarak rapor etmiştir. Yeterli kemik seviyesi bulunduğu zaman tercih edilen ve ideal prosedür olarak bildirilen anterior maksillaya 2 ila 4 geleneksel implant ile kombine yapılan zigomatik implantlarda başarı oranı \% 98-100 olarak rapor edilmiştir. ${ }^{29,}{ }^{34}$ Bedrossian ve ark. ${ }^{29} 34$ ay takipten oluşan çalışmalarında 44 zigomatik ve 80 premaksiller implant yerleştirmişler ve başarı oranını zigoma implantlarında \% 100 olarak rapor ederken geleneksel implantlarda bu oranı \% 91.25 olarak bildirmişlerdir. Benzer bir çalışmada Branemark ve ark. ${ }^{34} 28$ hastayı kapsayan ve 5-10 yıl süren takip çalışmalarında, zigoma implantlarında başarı oranını \% 94 geleneksel implantlarda ise bu oranı $\% 73$ olarak rapor etmişlerdir. Malevez ve ark. ${ }^{31}$ yaptıkları retrospektif bir çalışmada 55 hastaya yerleştirdikleri 103 zigoma implantının başarı oranını değerlendirmişlerdir. Yazarlar, protetik yüklemenin ardından 6-48 aylık takip döneminde hiçbir implantta fibrotik doku oluşumu izlenmediğini ve fonksiyonel olarak memnun edici sonuçlar elde ettiklerini bildirmişlerdir. Becktor ve ark. $^{33}$ ortalama takip periyodu 46.4 ay olan 16 hastayı kapsayan serilerinde 31 zigoma implantı yerleştirmişler ve sadece 3 (\% 9.7) implantın tekrarlayan sinüzitten dolayı kaybedildiğini bildirmişlerdir. Aynı çalışmada yazarlar yerleştirdikleri 74 geleneksel implantın ise 3 (\% 4.1) ünü osteointegrasyon periyodu esnasında kaybettiklerini rapor etmişlerdir.

\section{Zigoma İmplantlarının Avantaj ve Dezavantajları}

İleri derecede kemik rezorbsiyonu bulunan çenelerde sıkıkla tercih edilen kemik greftleme tekniğine alternatif bir yöntem olan zigoma implantı uygulamasının, greftleme yöntemiyle karşılaştırıldığında; ikinci bir cerrahi sahanın hiç oluşturulmaması ya da minimal seviyede olması, uzun tedavi süresinin önemli derecede azaltılması, proteze destek sağlayan toplam implant sayısının daha az olması nedeniyle daha az maliyete sahip olması gibi avantajları bulunmaktadır. ${ }^{3,18,35}$

Bununla birlikte zigomatik implant uygulamasl; teknik olarak zor bir cerrahiye sahip olması, göz ve komşu dokularına, fasiyal sinir, infraorbital sinir gibi komşu anatomik yapılara zarar verilme intimalinin olması, operasyon sonrası sinüzit gelişebilmesi, implantın primer stabilizasyonunun sağlanamaması ya da başarısı olması durumunda tekrar implant yerleştirilmesinin oldukça zor olması, cerrahi ulaşım güçlüğü, derin ya da genel anestezi gerektirmesi gibi dezavantajlara sahiptir. ${ }^{3,4,18,33}$

\section{SONUÇ}

Zigoma implantlarıyla ilgili çok fazla uzun dönem çalışması olmamasına rağmen posterior atrofik maksillaya sahip hastalarda destek amacıyla kullanıldıklarında yüksek oranda başarı elde edilmiştir. İkinci bir cerrahi oluşturmaması, tedavi süresini kısaltması gibi avantajlarından dolayı sinüs lift operasyonu ve kemik greftleme yöntemi ile augmentasyon prosedürüne alternatif bir teknik olarak kullanılabilmektedir. Zigoma implantları sık kullanılan bir tedavi yöntemi olmamakla beraber başarısını değerlendirmek ve sonuçlarını öngörebilmek için uzun takip dönemi içeren daha fazla çalışmaya intiyaç vardır.

\section{KAYNAKLAR}

1. Kreissl ME, Heydecke G, Metzger MC, Schoen R. Zygoma implant-supported prosthetic rehabilitation after partial maxillectomy using surgical navigation: a clinical report. J Prosthet Dent 2007;97:121-8.

2. Stievenart M, Malevez C. Rehabilitation of totally atrophied maxilla by means of four zygomatic implants and fixed prosthesis: a 6-40-month follow-up. Int J Oral Maxillofac Surg 2010;39:35863.

3. O'Connell JE, Cotter E, Kearns GJ. Maxillary reconstruction using zygomatic implants: a report of two cases. J Irish Dent Association 2011;57:146-55.

4. Kahnberg KE, Henry PJ, Hirsch JM, Ohrnell LO, Andreasson L, Branemark PI, et al. Clinical evaluation of the zygoma implant: 3-year follow-up at 16 clinics. J Oral Maxillofac Surg 2007;65:20338.

5. Xiaojun $C$, Ming $Y$, Yanping $L$, Yiqun W, Chengtao $W$. Image guided oral implantology and its application in the placement of zygoma implants. Comput Methods Programs Biomed 2009;93:16273.

6. Bedrossian E, Stumpel $\sqcup$, 3rd. Immediate 
stabilization at stage II of zygomatic implants: rationale and technique. J Prosthet Dent 2001;86:10-4.

7. Cordero EB, Benfatti CA, Bianchini MA, Bez LV, Stanley $K$, de Souza Magini R. The use of zygomatic implants for the rehabilitation of atrophic maxillas with 2 different techniques: Stella and Extrasinus. Oral Surg Oral Med Oral Pathol Oral Radiol Endod 2011;112:e49-53.

8. Sudhakar J, Ali SA, Karthikeyan S. Zygomatic Implants- A Review. J Indian Academy of Dent Specialist Res 2011;2:24-8.

9. Davo R, Malevez C, Rojas J. Immediate function in the atrophic maxilla using zygoma implants: a preliminary study. J Prosthet Dent 2007; Suppl 6: S44-51.

10. Ishak MI, Abdul Kadir MR, Sulaiman E, Abu Kasim $\mathrm{NH}$. Finite element analysis of different surgical approaches in various occlusal loading locations for zygomatic implant placement for the treatment of atrophic maxillae. Int J Oral Maxillofac Surg 2012.

11. Miglioranca RM, Sotto-Maior BS, Senna PM, Francischone CE, Cury AA. Immediate occlusal loading of extrasinus zygomatic implants: A prospective cohort study with a follow-up period of 8 years. Int J Oral Maxillofac Surg 2012.

12. Jensen OT, Leopardi A, Gallegos L. The case for bone graft reconstruction including sinus grafting and distraction osteogenesis for the atrophic edentulous maxilla. J Oral Maxillofac Surg 2004;62:1423-8.

13. Weischer T, Schettler D, Mohr C. Titanium implants in the zygoma as retaining elements after hemimaxillectomy. Int J Oral Maxillofac Implants 1997; 12:211-4.

14. Branemark PI. The Zygomaticus Fixture: clinical procedures. Nobel Biocare AB 1998.

15. Galan Gil S, Penarrocha Diago M, Balaguer Martinez J, Marti Bowen E. Rehabilitation of severely resorbed maxillae with zygomatic implants: an update. Med Oral Patol Oral Cir Bucal 2007; 12:E216-20.

16. Corvello PC, Montagner A, Batista FC, Smidt R, Shinkai RS. Length of the drilling holes of zygomatic implants inserted with the standard technique or a revised method: a comparative study in dry skulls. J Craniomaxillofac Surg 2011;39:119-23.
17. Davo R. Zygomatic implants placed with a twostage procedure: a 5-year retrospective study. Eur J Oral Implantol 2009;2:115-24.

18. Schow SR, Parel SM. The Zygoma Implant. In: Miloro M, editor. Peterson's Principles of Oral and Maxillofacial Surgery. London: BC Decker; 2004. p. 235-49.

19. Keller EE, Van Roekel NB, Desjardins RP, Tolman DE. Prosthetic-surgical reconstruction of the severely resorbed maxilla with iliac bone grafting and tissue-integrated prostheses. Int $\mathrm{J}$ Oral Maxillofac Implants 1987;2:155-65.

20. Montazem A, Valauri DV, St-Hilaire $H$, Buchbinder D. The mandibular symphysis as a donor site in maxillofacial bone grafting: a quantitative anatomic study. J Oral Maxillofac Surg 2000;581368-71.

21. Arrington ED, Smith WJ, Chambers HG, Bucknell $A L$, Davino NA. Complications of iliac crest bone graft harvesting. Clin Orthop Relat Res 1996:3009.

22. Penarrocha-Diago $M$, Uribe-Origone $R$, RamblaFerrer J, Guarinos-Carbo J. Fixed rehabilitation of a patient with hypohidrotic ectodermal dysplasia using zygomatic implants. Oral Surg Oral Med Oral Pathol Oral Radiol Endod 2004;98:161-5.

23. Schmidt BL, Pogrel MA, Young CW, Sharma A. Reconstruction of extensive maxillary defects using zygomaticus implants. J Oral Maxillofac Surg 2004;62:82-9.

24. Landes CA. Zygoma implant-supported midfacial prosthetic rehabilitation: a 4-year follow-up study including assessment of quality of life. Clin Oral Implants Res 2005;16:313-25.

25. Pham AV, Abarca M, De Mey A, Malevez C. Rehabilitation of a patient with cleft lip and palate with an extremely edentulous atrophied posterior maxilla using zygomatic implants: case report. Cleft Palate Craniofac J 2004;41:571-4.

26. Stella JP, Warner MR. Sinus slot technique for simplification and improved orientation of zygomaticus dental implants: a technical note. Int J Oral Maxillofac Implants 2000;15:889-93.

27. Aparicio C, Ouazzani W, Aparicio A, Fortes V, Muela $R$, Pascual $A$, et al. Extrasinus zygomatic implants: three year experience from a new surgical approach for patients with pronounced buccal concavities in the edentulous maxilla. Clin Implant Dent Relat Res 2010;12:55-61. 
28. Malo P, Nobre Mde A, Lopes I. A new approach to rehabilitate the severely atrophic maxilla using extramaxillary anchored implants in immediate function: a pilot study. J Prosthet Dent 2008;100:354-66.

29. Bedrossian E, Stumpel L, 3rd, Beckely ML, Indresano $\mathrm{T}$. The zygomatic implant: preliminary data on treatment of severely resorbed maxillae. A clinical report. Int J Oral Maxillofac Implants 2002;17:861-5.

30. Davo R, Malevez C, Rojas J, Rodriguez J, Regolf J. Clinical outcome of 42 patients treated with 81 immediately loaded zygomatic implants: a $12-$ to 42-month retrospective study. Eur J Oral Implantol 2008;1:141-50.

31. Malevez C, Abarca M, Durdu F, Daelemans P. Clinical outcome of 103 consecutive zygomatic implants: a 6-48 months follow-up study. Clin Oral Implants Res 2004;15:18-22.

32. Kurkcuoglu I, Koroglu A, Ozkır SE. The criteria and evaluation methods for success of dental Implants. J Dent Fac Atatürk Uni 2010;20:221-9.

33. Becktor JP, Isaksson $S$, Abrahamsson P, Sennerby L. Evaluation of 31 zygomatic implants and 74 regular dental implants used in 16 patients for prosthetic reconstruction of the atrophic maxilla with cross-arch fixed bridges. Clin Implant Dent Relat Res 2005;7:159-65.

34. Branemark PI, Grondahl K, Ohrnell LO, Nilsson P, Petruson B, Svensson B, et al. Zygoma fixture in the management of advanced atrophy of the maxilla: technique and long-term results. Scand J Plast Reconstr Surg Hand Surg 2004;38:70-85.

35. Chow J, Hui E, Lee PK, Li W. Zygomatic implants-protocol for immediate occlusal loading: a preliminary report. J Oral Maxillofac Surg 2006;64:804-11.

\section{Yazışma Adresi:}

Yrd. Doç. Dr. M. Melih ÖMEZLİ

Ordu Üniversitesi, Diş Hekimliği Fakültesi, Ağız Diş ve Çene Cerrahisi AD, 52100 ORDU

TIf: İş: 04522361289

Cep tlf: 05065364288

E-posta: mmelihomezli@hotmail.com 